\title{
Use of Odd and Branched-Chain Fatty Acids in Rumen Contents and Milk as a Potential Microbial Marker
}

\author{
B. Vlaeminck, ${ }^{1}$ C. Dufour, ${ }^{1}$ A. M. van Vuuren, ${ }^{2}$ A. R. J. Cabrita, ${ }^{3}$ \\ R. J. Dewhurst, ${ }^{4}$ D. Demeyer, ${ }^{1}$ and V. Fievez ${ }^{1}$ \\ ${ }^{1}$ Laboratory for Animal Nutrition and Animal Product Quality, \\ Ghent University, 9090 Melle, Belgium \\ ${ }^{2}$ Nutrition and Food, Animal Sciences Group, Wageningen UR, \\ 8200 AB Lelystad, The Netherlands \\ ${ }^{3}$ CECA/ICETA, Faculdade de Ciências, Universidade do Porto, \\ Rua Padre Armando Quintas, 4485-661 Vairão VC, Portugal \\ ${ }^{4}$ Institute of Grassland and Environmental Research, Plas Gogerddan, \\ Aberystwyth, SY23 3EB, UK
}

\section{ABSTRACT}

The objectives of this study were: 1 ) to determine if a correlation exists between rumen odd and branchedchain fatty acids (OBCFA, i.e., $\mathrm{C}_{15: 0}$, iso $\mathrm{C}_{15: 0}$, anteiso $\mathrm{C}_{15: 0}, \mathrm{C}_{17: 0}$, iso $\mathrm{C}_{17: 0}$, anteiso $\mathrm{C}_{17: 0}$, and $\mathrm{C}_{17: 1}$ ), uracil, and purine bases (PB), 2) to evaluate the potential of milk OBCFA secretion to predict duodenal flow of microbial protein in lactating cows, 3) to evaluate the accuracy of the latter prediction equations using an independent data set, and 4) to determine whether these predictions were more accurate than predictions based on dry matter intake (DMI) and dietary characteristics. In the first experiment, 4 lactating dairy cows arranged in a $4 \times 4$ Latin square were offered diets based on grass silages of different botanical composition and a standard concentrate. The relationship between rumen pool size of OBCFA and microbial matter was investigated. Rumen pool size of microbial matter (g), determined 4, 12, and $17 \mathrm{~h}$ after feeding, using uracil and $\mathrm{PB}$ as microbial markers, was closely related to OBCFA $(\mathrm{g})\left[\mathrm{r}^{2}=0.716\right.$, root mean square error $(\mathrm{RMSE})=4.45$ ] . To correct for differences in marker concentrations among strains of rumen microbes, $\mathrm{C}_{17: 0}$ was included in the regression equations, resulting in an increased predictive power $\left(r^{2}=0.780\right.$, RMSE $=$ 3.92). The relationship between microbial flow to the duodenum and milk OBCFA yield was evaluated in a second experiment with lactating dairy cows offered diets based on grass silage and concentrates differing in starch source. Similar to observations in the rumen, milk OBCFA yield was closely related to microbial flow to the duodenum (RMSE $=4.28$ ), but predictive power of equations did not increase when straight-

Received July 2, 2004.

Accepted November 18, 2004.

Corresponding author: V. Fievez; e-mail: veerle.fievez@UGent.be.

chain $\mathrm{C}_{17}$-fatty acids were included in the regression equations (RMSE $=4.92$ ). Evaluation of the current prediction equations with 3 independent datasets resulted in a root mean square prediction error of 20.5 and $13.4 \%$ of the observed mean for equations based on milk secretion of total OBCFA and straight-chain $\mathrm{C}_{17}$-fatty acids, respectively. Comparison of the accuracy of the latter equations with 2 previously published equations based on DMI and dietary characteristics suggest the former to be more accurate. This first evaluation suggests that milk OBCFA could be used as a marker for duodenal flow of microbial matter, especially when accurate measurements of DMI are not available.

(Key words: odd and branched-chain fatty acids, microbial protein, dairy cattle, milk)

Abbreviation key: $\mathbf{C C C}=$ concordance correlation coefficient, $\mathbf{C V}=$ coefficient of variation, DAPA = diaminopimelic acid, MSPE = mean square prediction error, OBCFA = odd and branched-chain fatty acids, PB = purine bases, RMSE = root mean square error .

\section{INTRODUCTION}

Protein available to the ruminant for duodenal absorption is supplied by dietary bypass protein, endogenous protein secretions, and microbial protein. The latter supplies, on average, 59\% of the protein available for absorption in dairy cattle (Clark et al., 1992). The major importance of microbial protein to the ruminant has been determined from experiments involving surgically cannulated animals. However, cannulation is costly, increases animal care concerns, and can lower DMI and milk production (MacRae and Wilson, 1977). Hence, both in practical dairy cattle feeding as well as for research purposes, the development of noninvasive methods providing insight in the duode- 
nal supply of microbial protein is of enormous importance.

Several reports have been published on the use of urinary and milk allantoin excretion to estimate duodenal flow of microbial protein (reviewed by Dewhurst et al., 2000). Although milk allantoin seems most promising as an on-farm diagnostic tool, its use is obscured by its auto-correlation with milk yield (Dewhurst et al., 2000), underlining the need for research on other milk constituents as markers for the duodenal flow of microbial nitrogen.

The fatty acid composition of rumen bacteria is characterized by a large proportion of odd and branchedchain fatty acids (OBCFA) in their membrane lipids (pentadecanoic acid, $\mathrm{C}_{15: 0}$; iso methyltetradecanoic acid, iso $\mathrm{C}_{15: 0}$; anteiso methyltetradecanoic acid, anteiso $\mathrm{C}_{15: 0}$; heptadecanoic acid, $\mathrm{C}_{17: 0}$; iso methylhexadecanoic acid, iso $\mathrm{C}_{17: 0}$; anteiso methylhexadecanoic acid, anteiso $\mathrm{C}_{17: 0}$, and heptadecenoic acid, $\mathrm{C}_{17: 1}$ ) (Kaneda, 1991). Microbial odd chain fatty acids $\left(\mathrm{C}_{15: 0}\right.$ and $\left.\mathrm{C}_{17: 0}\right)$ are formed through elongation of propionate or valerate, whereas precursors of branched-chain fatty acids (iso $\mathrm{C}_{15: 0}$, iso $\mathrm{C}_{17: 0}$, anteiso $\mathrm{C}_{15: 0}$, anteiso $\mathrm{C}_{17: 0}$ ) are branched-chain amino acids (valine, leucine, and isoleucine) and their corresponding branched short-chain carboxylic acids (isobutyric, isovaleric, and 2-methyl butyric acid) (Kaneda, 1991). In 1962, Keeney et al. suggested that the major source of these fatty acids in ruminant milk is from rumen bacterial origin rather than from animal synthesis. Although odd chain fatty acids or their anteiso isomers can be synthesized through incorporation of propionyl-CoA instead of acetyl-CoA, or methylmalonyl-CoA instead of malonyl$\mathrm{CoA}$, respectively, the contribution of the latter processes to OBCFA in milk from dairy cows is assumed negligible (Croom et al., 1981; Massart-Leën et al., 1983).

Hence, Keeney et al. (1962) suggested that bacterial OBCFA might be used as markers to quantify bacterial matter leaving the rumen. Since then, little attention has been paid to these fatty acids in ruminant research, but recently their presence in milk has been related to differences in feeding strategies (Dewhurst et al., 2000; Cabrita et al., 2003b) and rumen fermentation pattern (Vlaeminck et al., 2003). Moreover, based on large differences in microbial OBCFA profiles, Keeney et al. (1962) and Dewhurst et al. (2000) suggested that OBCFA in duodenal digesta and milk could provide a qualitative description of the proportions of different classes of microbes leaving the rumen.

The objective of this work was to evaluate the potential of OBCFA to predict duodenal flow of microbial matter. For this purpose, data from 2 feeding experi-
Table 1. The amounts of different silages used in the 4 treatment diets (experiment 1 ).

\begin{tabular}{lrrrr}
\hline & \multicolumn{4}{c}{ Treatment diet } \\
\cline { 2 - 5 } Silage $(\mathrm{g} / \mathrm{kg}$ of $\mathrm{DM})$ & $100 \mathrm{IM}$ & $20 \mathrm{MB}$ & $60 \mathrm{MB}$ & $60 \mathrm{HR}$ \\
\hline Intensively managed grassland & 1000 & 800 & 400 & 400 \\
Meadow bird grassland & 0 & 200 & 600 & 0 \\
Herb-rich grassland & 0 & 0 & 0 & 600 \\
\hline
\end{tabular}

ments were used. Firstly, in experiment 1 (Bruinenberg et al., 2004), the relationship was investigated between the amounts of OBCFA and microbial matter in rumen contents, using purine bases $(\mathbf{P B})$ and uracil as reference markers. Secondly, duodenal flow of microbial matter, using diaminopimelic acid (DAPA) and $\mathrm{PB}$ as reference markers, was related to milk secretion of OBCFA in experiment 2 (Hindle et al., accepted; van Vuuren et al., 2004). Thirdly, the relationships established in experiment 2 were validated using data of the experiments reported by Cabrita et al. $(2003 a, b)$. Finally, the predictive precision based on milk OBCFA was compared with that of previously published equations based on DMI and dietary characteristics (Oldick et al., 1999; Gosselink et al., 2003).

\section{MATERIALS AND METHODS}

\section{Experimental Design, Diets, and Sampling}

Experiment 1. Experimental procedures were described in detail previously (Bruinenberg et al., 2004). Briefly, 4 rumen-fistulated multiparous Holstein cows (647 $\pm 69 \mathrm{~kg} \mathrm{BW} ; 249 \pm 76$ DIM at the beginning of the experiment) were assigned to a $4 \times 4$ Latin square experiment. Each experimental period lasted for $21 \mathrm{~d}$. Forages differed between the 4 dietary treatments and consisted of different combinations of 3 grassland silages (Table 1). The latter were obtained from one intensively managed grassland and 2 seminatural grasslands: one species-poor, composed mainly of meadow bird grass, and the other species-rich, consisting of $34 \%$ nonleguminous herbs, $11 \%$ legume, and $55 \%$ grasses on a DM basis. Cows were fed (twice daily) silage and a protein-rich concentrate $(4.5 \mathrm{~kg}$ of DM/ d). The mean intake of silages was $14.0 \mathrm{~kg}$ of DM/d (on average, 13.9, 14.2, 13.9, and $13.7 \mathrm{~kg}$ of DM for diets $1,2,3$, and 4, respectively). At 0600 and $1600 \mathrm{~h}$, cows received 40 and $60 \%$ of the daily DM offered, respectively. After a 2-wk adaptation period, rumen contents were manually evacuated 4,12 , and $17 \mathrm{~h}$ after feeding. At each sampling time, ruminal contents were weighed and mixed thoroughly, and a subsample was frozen. 
Experiment 2. Experimental procedures were described previously (Hindle et al., accepted; van Vuuren et al., 2004). Briefly, 4 rumen- and duodenal-fistulated Holstein cows $(590 \pm 14 \mathrm{~kg} \mathrm{BW} ; 80 \pm 18 \mathrm{DIM}$ at the beginning of the experiment) were fed 4 treatment diets in a $4 \times 4$ Latin Square design. Each experimental period lasted for $28 \mathrm{~d}$, of which the first 2 wk were for adaptation. The control diet consisted of grass silage ( $43 \%$ of DM), ensiled sugar beet pulp ( $11 \%$ of DM), and a concentrate mixture with $70 \%$ dried sugar beet pulp. Dried sugar beet pulp of the concentrate was replaced by native potato starch, corn meal, or wheat meal in each of the 3 experimental diets. Diets were distributed twice daily in equal portions as a TMR at 0600 and 1700 h. Duodenal and milk samples were taken during the final week of each experimental period. A representative sample of duodenal digesta was constituted from 12 subsamples per cow. Subsamples were removed during 2 consecutive days, every $4 \mathrm{~h}$ ( 0 , $4,8,12,16,20,2,6,10,14,18$, and $22 \mathrm{~h}$ after the morning feeding). For each experimental period, the 12 duodenal subsamples were pooled (1 sample/cow per treatment) and stored frozen. Milk samples were taken from 8 consecutive milkings and stored frozen. Duodenal flows were determined based on the double marker technique as described by Faichney (1992), using Cr-mordanted NDF and CoEDTA for the solid and liquid fractions, respectively. After a priming dose of $90 \mathrm{~g}$ of $\mathrm{Cr}-\mathrm{NDF}$ and $22.5 \mathrm{~g}$ of CoEDTA, markers (60 $\mathrm{g}$ of $\mathrm{Cr}-\mathrm{NDF}$ and $15 \mathrm{~g}$ of CoEDTA per d) were administered in 2 equal portions per $d$ via the rumen cannula at 0500 and $1600 \mathrm{~h}$ for $11 \mathrm{~d}$. In the fourth week of each period, markers were administered at 4$\mathrm{h}$ intervals to prevent large variation in marker concentrations in the duodenum.

\section{Analyses}

Rumen and duodenal contents were freeze-dried before analysis. Purine bases and uracil were extracted from freeze-dried samples using perchloric acid, as described by Makkar and Becker (1999). In detail, $0.5 \mathrm{~g}$ of freeze-dried rumen or duodenal sample was weighed into a $25-\mathrm{mL}$ screw-cap tube and hydrolyzed for $1 \mathrm{~h}$ at $95^{\circ} \mathrm{C}$, using $3 \mathrm{~mL}$ of $12 \mathrm{M}$ perchloric acid. After cooling, $25 \mathrm{~mL}$ of $\mathrm{H}_{2} \mathrm{O}$ was added and vortexed and the contents of the tube were filtered (S\&S 589/2, Schleicher \& Schuell MicroScience, Dassel, Germany), with recovery of the filtrate in a $50-\mathrm{mL}$ volumetric flask. The final volume was brought to $50 \mathrm{~mL}$ using $\mathrm{H}_{2} \mathrm{O}$. Part of the final solution was filtered $(0.22-\mu \mathrm{m}$ filter, Alltech, Lokeren, Belgium) and used for determination of PB and uracil by HPLC with a Partisil SCX column $(10 \mu \mathrm{m}, 250 \times 4.6 \mathrm{~mm}$, Alltech $)$ guarded with a precolumn $(7.5 \times 4.6 \mathrm{~mm}$, Alltech). The buffer solution $\left(0.01 \mathrm{M} \mathrm{KH}_{2} \mathrm{PO}_{4}\right)$ was run isocratically at 1 $\mathrm{mL} / \mathrm{min}$ and the effluent monitored at $250 \mathrm{~nm}$. Hydrolysis and analyses were performed in duplicate. Although the rumen microbes were not isolated from the rumen contents before uracil and $\mathrm{PB}$ analyses, contribution of nonmicrobial nucleic acids was assumed negligible $4 \mathrm{~h}$ after feeding (McAllan, 1982). Hence, both uracil and PB were used as references for changes in the amount of rumen microbial matter. Duodenal DAPA was analyzed according to Moore et al. (1985).

Lipids were extracted from $2.5 \mathrm{~g}$ of freeze-dried rumen contents using chloroform:methanol (2:1, vol/vol), adopted from Folch et al. (1957). Fatty acids in extracted lipids were methylated with $\mathrm{NaOH}$ in metha$\mathrm{nol}(0.5 \mathrm{~mol} / \mathrm{L})$ followed by $\mathrm{HCl}$ in methanol (1/1; vol/ vol) (Raes et al., 2001). Nonadecanoic acid (Sigma, Bornem, Belgium) was used as the internal standard. The fatty acid methyl esters were extracted twice with $2 \mathrm{~mL}$ of hexane, and pooled extracts were evaporated to dryness under $\mathrm{N}_{2}$. The residue was dissolved in 1 $\mathrm{mL}$ of hexane.

Milk fat from thawed milk was extracted by the Röse-Gottlieb procedure (ISO-3889). Briefly, a homogenized sample $(10 \mathrm{~g})$ was weighed into a Mojonniertype fat-extraction flask. Ammonium hydroxide solution $(2 \mathrm{~mL})$ was added and the mixture was shaken vigorously. Further, in a first extraction step, $10 \mathrm{~mL}$ of ethanol, $25 \mathrm{~mL}$ of diethyl ether, and $25 \mathrm{~mL}$ of petroleum ether were added and mixed gently. During the second extraction step, $5 \mathrm{~mL}$ of ethanol, $15 \mathrm{~mL}$ of diethyl ether, and $15 \mathrm{~mL}$ of petroleum ether was used, and only diethyl and petroleum ether $(15 \mathrm{~mL})$ were used during the final extraction step. After each extraction step, the supernatant was transferred into fat-collecting vessels after phase separation (30 min). The solvent was evaporated using a rotary evaporator at room temperature, and the extracted lipids were resolved in $20 \mathrm{~mL}$ of diethyl ether:petroleum ether (1:1, vol/vol). Tridecanoic and nonadecanoic acid (Sigma) were used as the internal standards and added before methylation. Fatty acids in extracted lipids were methylated as described previously. The fatty acid methyl esters were extracted twice with $2 \mathrm{~mL}$ of hexane. From the pooled extracts, $1 \mathrm{~mL}$ was analyzed immediately by gas chromatography for short- and medium-chain fatty acids $\left(\mathrm{C}_{4: 0}, \mathrm{C}_{6: 0}, \mathrm{C}_{8: 0}\right.$, and $\left.\mathrm{C}_{10: 0}\right)$, and the reminder was evaporated to dryness under $\mathrm{N}_{2}$. The residue was dissolved in $1 \mathrm{~mL}$ of hexane.

The methylated fatty acids were analyzed on a Hewlett-Packard 6890 gas chromatograph (Hewlett-Packard Co., Brussels, Belgium) with a CP-Sil88 column for fatty acid methyl esters $(100 \mathrm{~m} \times 0.25 \mathrm{~mm} \times 0.2$ 
$\mu \mathrm{m}$; Chrompack Inc., Middelburg, the Netherlands). For ruminal fatty acids, the following temperature program was used: $150^{\circ} \mathrm{C}$ for $2 \mathrm{~min}$, followed by an increase at $1^{\circ} \mathrm{C} / \mathrm{min}$ to $158^{\circ} \mathrm{C}$, held at $158^{\circ} \mathrm{C}$ for 28 min, then increased at $1^{\circ} \mathrm{C} / \mathrm{min}$ to $196^{\circ} \mathrm{C}$. For milk samples, the following temperature program was used: $70^{\circ} \mathrm{C}$ for $4 \mathrm{~min}$, followed by an increase at $10^{\circ} \mathrm{C} /$ $\min$ to $150^{\circ} \mathrm{C}$, then increased at $1^{\circ} \mathrm{C} / \mathrm{min}$ to $165^{\circ} \mathrm{C}$, held at $165^{\circ} \mathrm{C}$ for $20 \mathrm{~min}$, increased at $2^{\circ} \mathrm{C} / \mathrm{min}$ to $170^{\circ} \mathrm{C}$, held at $170^{\circ} \mathrm{C}$ for $10 \mathrm{~min}$, increased at $4^{\circ} \mathrm{C} / \mathrm{min}$ to $215^{\circ} \mathrm{C}$, and held at $215^{\circ} \mathrm{C}$ for $20 \mathrm{~min}$. Peaks were identified based on their retention times, corresponding with the standards (Sigma and NuChek Prep, Elysian, MN). Standard curves to determine the response factors for milk short-chain fatty acids were determined daily. Short-chain fatty acids in milk were quantified using tridecanoic acid as internal standard, whereas the other fatty acids were quantified with nonadecanoic acid.

\section{Calculations}

Independent data set to evaluate accuracy of prediction. Predictive equations can only be evaluated properly by the means of an independent experiment. However, data on milk OBCFA are still very scarce. Hence, data from the experiments described by Cabrita et al. $(2003 a, b)$ were used to evaluate the accuracy of the predictive equations, although duodenal flow of microbial matter was not measured directly in these experiments but evaluated using the allantoin/creatinine ratio in spot urine samples. Hence, duodenal flow of PB in the independent data set (Cabrita et al., 2003a,b) was calculated from the allantoin/creatinine ratio in spot urine samples, assuming a constant daily urinary excretion of creatinine $(931 \mu \mathrm{mol} /$ kg BW ${ }^{0.75}$; Gonzalez-Ronquillo et al., 2003), a constant endogenous purine derivative contribution $(385 \mu \mathrm{mol} /$ $\mathrm{kg} \mathrm{BW}^{0.75}$; Chen and Gomes, 1995), and the relation of urinary excretion of purine derivatives with duodenal flow of PB as described in Gonzalez-Ronquillo et al. (2003). Consequently, a number of assumptions have been made to calculate "actual" duodenal flow of microbial matter from measured urinary allantoin/creatinine ratios (e.g., daily creatinine excretion and endogenous allantoin excretion) in the independent data set (Cabrita et al., 2003a,b). Nevertheless, even with the assumptions made, relative differences in microbial flow, induced by dietary or animal factors, still might be evaluated and related to milk OBCFA secretion.

Prediction of duodenal flow of microbial matter using published equations based on DMI and dietary characteristics. Furthermore, previously published equations based on DMI and dietary charac- teristics as described by Oldick et al. (1999) [equation 10 in Oldick et al. (1999); microbial PB $(\mathrm{g} / \mathrm{d})=[16.1$ $+22.9 \times \mathrm{DMI}(\mathrm{kg} / \mathrm{d})-0.365 \times \mathrm{DMI}(\mathrm{kg} / \mathrm{d}) \times \mathrm{DMI}(\mathrm{kg} /$ d) $-0.174 \times \mathrm{NDF}(\mathrm{g} / \mathrm{kg}$ of $\mathrm{DM})] \times 0.147]$ and Gosselink et al. (2003) [equation 3 in Gosselink et al. (2003); microbial PB $(\mathrm{g} / \mathrm{d})=(7.80+0.000119 \times$ crude protein $(\mathrm{g} / \mathrm{kg}$ of $\mathrm{DM})) \times \mathrm{DMI}(\mathrm{kg} / \mathrm{d}) \times 0.147]$ were used as an alternative to predict duodenal flow of microbial matter. As the equations described by Oldick et al. (1999) and Gosselink et al. (2003) were originally expressed as duodenal flow of microbial $\mathrm{N}$, the values were converted to duodenal flow of $\mathrm{PB}$ using a $\mathrm{PB}$-to-N ratio in mixed rumen bacteria of 0.147 (Clark et al., 1992; Perez et al., 1997; Volden et al., 1999; Martin-Orue et al., 2000).

\section{Statistical Analyses}

All statistical analyses were performed using SPSS 11.0 (SPSS software for Windows, release 11.0, SPSS, Inc., Chicago, IL).

Univariate analysis. A split-plot analysis for repeated measures was used to evaluate the effect of dietary treatment, cow, experimental period, and sampling time on rumen pool size of OBCFA, uracil, and $\mathrm{PB}$ in experiment 1 according to:

$$
\mathrm{Y}_{\mathrm{ijk} l}=\mu+\mathrm{T}_{\mathrm{i}}+\mathrm{P}_{\mathrm{j}}+\mathrm{C}_{\mathrm{k}}+\mathrm{S}_{\mathrm{l}}+\mathrm{TS}_{\mathrm{il}}+\mathrm{PS}_{\mathrm{jl}}+\mathrm{CS}_{\mathrm{kl}}+\varepsilon_{\mathrm{ijk}}
$$

where $\mathrm{Y}_{\mathrm{ijkl}}$ is the individual observation, $\mu$ the overall mean, $T_{i}$ the effect of dietary treatment, $P_{j}$ the effect of experimental period, $\mathrm{C}_{\mathrm{k}}$ the effect of cow, $\mathrm{S}_{1}$ the effect of sampling time, $\mathrm{TS}_{\mathrm{il}}$ the interaction between treatment and sampling time, $\mathrm{PS}_{\mathrm{j} 1}$ the interaction between period and sampling time, $\mathrm{CS}_{\mathrm{kl}}$ the interaction between cow and sampling time, and $\varepsilon_{\mathrm{ijkl}}$ the residual error. Sampling time was the repeated measure. Duncan's multiple range test was performed to evaluate differences between dietary treatments.

Differences in duodenal flow of DAPA and PB and milk secretion of OBCFA from experiment 2 were evaluated according to:

$$
\mathrm{Y}_{\mathrm{ijk}}=\mu+\mathrm{T}_{\mathrm{i}}+\mathrm{P}_{\mathrm{j}}+\mathrm{C}_{\mathrm{k}}+\varepsilon_{\mathrm{ijk}}
$$

where $\mathrm{Y}_{\mathrm{ijk}}$ is the individual observation, $\mu$ the overall mean, $T_{i}$ the effect of dietary treatment, $P_{j}$ the effect of experimental period, $\mathrm{C}_{\mathrm{k}}$ the effect of cow, and $\varepsilon_{\mathrm{ijk}}$ the residual error. Effect of period and cow were treated as random effects. Duncan's multiple range test was performed to evaluate differences between dietary treatments. For milk OBCFA, means were calculated per cow and diet from 8 analyses. 
Table 2. Rumen pool sizes of purine bases, uracil, odd and branched-chain fatty acids (OBCFA) and $\mathrm{C}_{17: 0}$ in rumen content of dairy cows fed different grass silages (experiment 1).

\begin{tabular}{|c|c|c|c|c|c|c|c|c|c|c|c|}
\hline & \multicolumn{3}{|c|}{ Time after feeding, $\mathrm{h}$} & \multicolumn{4}{|c|}{ Treatment $^{1}$} & \multirow[b]{2}{*}{$\mathrm{SEM}^{3}$} & \multicolumn{3}{|c|}{$P$ value ${ }^{2}$} \\
\hline & 4 & 12 & 17 & $100 \mathrm{IM}$ & $20 \mathrm{MB}$ & $60 \mathrm{MB}$ & $60 \mathrm{HR}$ & & Diet & Animal & Time \\
\hline $\mathrm{n}$ & 16 & 16 & 16 & 12 & 12 & 12 & 12 & & & & \\
\hline Purine bases, $\mathrm{g}$ & $34.1^{\mathrm{c}}$ & $29.3^{\mathrm{b}}$ & $23.6^{\mathrm{a}}$ & $34.0^{\mathrm{b}}$ & $32.1^{\mathrm{b}}$ & $25.4^{\mathrm{a}}$ & $24.6^{\mathrm{a}}$ & 1.13 & 0.002 & 0.001 & 0.003 \\
\hline Uracil, g & $9.55^{\mathrm{c}}$ & $8.41^{\mathrm{b}}$ & $6.62^{\mathrm{a}}$ & $9.82^{\mathrm{b}}$ & $9.06^{\mathrm{b}}$ & $7.08^{\mathrm{a}}$ & $6.80^{\mathrm{a}}$ & 0.364 & 0.003 & 0.001 & 0.001 \\
\hline OBCFA, $\mathrm{g}$ & $20.8^{\mathrm{b}}$ & $21.4^{\mathrm{b}}$ & $16.8^{\mathrm{a}}$ & $24.6^{\mathrm{c}}$ & $21.1^{\mathrm{b}}$ & $17.3^{\mathrm{a}}$ & $15.8^{\mathrm{a}}$ & 0.94 & 0.002 & 0.001 & 0.035 \\
\hline $\mathrm{C}_{17: 0}, \mathrm{~g}$ & $2.68^{\mathrm{b}}$ & $2.64^{\mathrm{b}}$ & $1.89^{\mathrm{a}}$ & $2.74^{\mathrm{b}}$ & $2.54^{\mathrm{b}}$ & $2.16^{\mathrm{a}}$ & $2.18^{\mathrm{a}}$ & 0.086 & 0.008 & 0.001 & 0.003 \\
\hline
\end{tabular}

\footnotetext{
a,b,c Means of sampling time after feeding or of dietary treatment effects lacking a common superscript within a row differ significantly $(P<0.05)$.

${ }^{1}$ Treatments include grass silage from $100 \%$ intensively managed grassland (100IM), 80\% intensively managed grassland and 20\% meadow bird grassland (20MB), $40 \%$ intensively managed grassland and $60 \%$ meadow bird grassland (60MB), and 40\% intensively managed grassland and 60\% herb-rich grassland (60HR).

${ }^{2}$ Effect of dietary treatment, animal, and time after feeding.

${ }^{3} \mathrm{SEM}=$ Standard error of the dietary treatment means $(\mathrm{n}=12)$.
}

Linear regression analyses. In experiment 1 , individual data were used for linear regression analyses. For milk OBCFA in experiment 2, means were calculated per cow and diet from 8 analyses. The backward elimination procedure of multiple regression was performed using the regression procedure of SPSS to develop equations to predict microbial matter in rumen (experiment 1) and duodenal flow of microbial matter (experiment 2).

Regression equations were evaluated based on the root mean square error (RMSE) and coefficients of variation (CV). Moreover, a first evaluation of the prediction accuracy of the regression equations was performed using the statistic PRESS (Rawlings, 1988). This statistic is computed as follows:

$$
\operatorname{PRESS}=\sum_{i=1}^{n}\left(y_{\mathrm{i}}-\hat{y}_{i,-i}\right)^{2}
$$

where $y_{i}$ is the $i$ th observation for the dependent variable, $\hat{y}_{i,-i}$ is the prediction of observation $i$ using a model estimated without the $i$ th observation, and $n$ is the number of observations in the data set used for parameter estimation. The statistic PRESS divided by $\mathrm{n}$ can be considered an estimate of the mean square prediction error (MSPE). Although this statistic cannot detect lack of accuracy due to inadequacies of the sample used to represent the population studied, the MSPE estimate is useful when independent datasets are not available (Rawlings, 1988).

Independent datasets to evaluate accuracy of prediction. The regression equations developed in this study were validated with independent datasets using the MSPE (Bibby and Toutenberg, 1977):

$$
M S P E=\frac{1}{n} \times \sum_{i=1}^{n}\left(y_{i}-\hat{y}_{i}\right)^{2}
$$

where $n$ is the number of observations, and $y_{i}$ and $\hat{y}_{i}$ are the observed and predicted values, respectively. The square root of MSPE is expressed in the same units as the observed values and a comparison of the root MSPE as a percentage of the observed mean provides an indication of the overall error of prediction.

Accuracy and precision of the equations were further evaluated based on the concordance correlation coefficient (CCC) (Lin, 1989; St-Pierre, 2003). The CCC is calculated as:

$$
\rho_{c}=\rho \times C_{b}
$$

with $\rho_{c}$ the concordance correlation coefficient, $\rho$ the Pearson correlation coefficient, and $\mathrm{C}_{\mathrm{b}}$ the bias correction factor which is calculated as:

$$
C_{b}=\frac{2 \sigma_{o} \sigma_{p}}{\sigma_{o}^{2}+\sigma_{p}^{2}+\left(\mu_{o}-\mu_{p}\right)^{2}}
$$

with $\sigma_{o}$ and $\sigma_{p}$ the standard deviation of the observed and predicted values, respectively, and $\mu_{o}$ and $\mu_{p}$ the observed and predicted mean. The Pearson correlation coefficient reflects precision, i.e., the degree to which individual predictions cluster about the regression line. The bias correction factor reflects accuracy, i.e., the degree to which the regression line adheres to the $45^{\circ}$ line through the origin (the concordance line). The $\mathrm{CCC}$ reflects the degree to which individual predictions adhere to the concordance line. The bias correction factor consists of a scale shift $\left(=\sigma_{o} / \sigma_{p}\right)$ and a loca- 
tion shift relative to the scale $\left(=\left[\mu_{o}-\mu_{p}\right] /\left[\sigma_{o} \times \sigma_{p}\right]^{1 / 2}\right)$ (Lin, 1989; St-Pierre, 2003).

Comparison with previously published prediction equations. Using the same independent datasets, the accuracy of prediction equations based on milk secretion of OBCFA, developed in this study, was compared with predictions by 2 previous published equations (Oldick et al., 1999; Gosselink et al., 2003).

\section{RESULTS AND DISCUSSION}

\section{Relationship of Rumen PB and Uracil with OBCFA (Experiment 1)}

Rumen pool size of $P B$ and uracil. Effects of treatment and time after feeding on rumen pool sizes of $\mathrm{PB}$ and uracil are presented in Table 2. Dietary treatments with $40 \%$ grass silage from intensively managed grassland showed smaller pool sizes of both PB and uracil, which decreased with time after feeding. As could be expected, rumen pool sizes of $\mathrm{PB}$ and uracil were closely related $\left[\mathrm{PB}(\mathrm{g})=3.54_{(\mathrm{SE}}=0.051\right) \times$ uracil $\left.(\mathrm{g}), \mathrm{n}=48, \mathrm{r}^{2}=0.991, \mathrm{RMSE}=2.90\right]$.

Relation of rumen pool size of OBCFA with $P B$ and uracil. Rumen pool sizes of OBCFA decreased with decreasing proportions of silage from intensively managed grassland (Table 2). Changes in rumen pool size of OBCFA were closely associated with changes in uracil and $\mathrm{PB}$, confirming the potential of OBCFA to predict rumen pool size of microbial matter (Table 3 ; Figure 1). A plot of predicted vs. residual values (i.e., observed values - predicted values) did not reveal any pattern (data not shown). Patterns in residuals can indicate that the assumptions of regression procedures are not met or that required independent variables are missing (Draper and Smith, 1981).

The strong relationship of rumen OBCFA to microbial matter is in agreement with results of Viviani et al. (1967), from which we could calculate a similar positive relationship between OBCFA and DNA in rumen contents. The slopes of the equations (equations 1 and 3 in Table 3) suggest the ratios PB:OBCFA and uracil:OBCFA in mixed rumen bacteria are 1.16 and 0.34 , respectively. Bas et al. (2003) reported a mean OBCFA content of $8.97 \mathrm{~g} / \mathrm{kg}$ of DM in mixed rumen bacteria. Assuming PB and uracil contents of 10.5 and $2.59 \mathrm{~g} / \mathrm{kg}$ of DM, respectively (Perez et al., 1997; Volden et al., 1999; Martin-Orue et al., 2000), we calculated the ratios PB:OBCFA and uracil:OBCFA in mixed rumen bacteria to be 1.17 and 0.29 , respectively. Obviously, the ratios observed in this experiment are in line with these calculations. Nevertheless, the ratios are clearly susceptible to variation as indicated by the estimated root MSPE of 16.4 and $14.6 \%$ of the observed mean for prediction of $\mathrm{PB}$ and uracil,

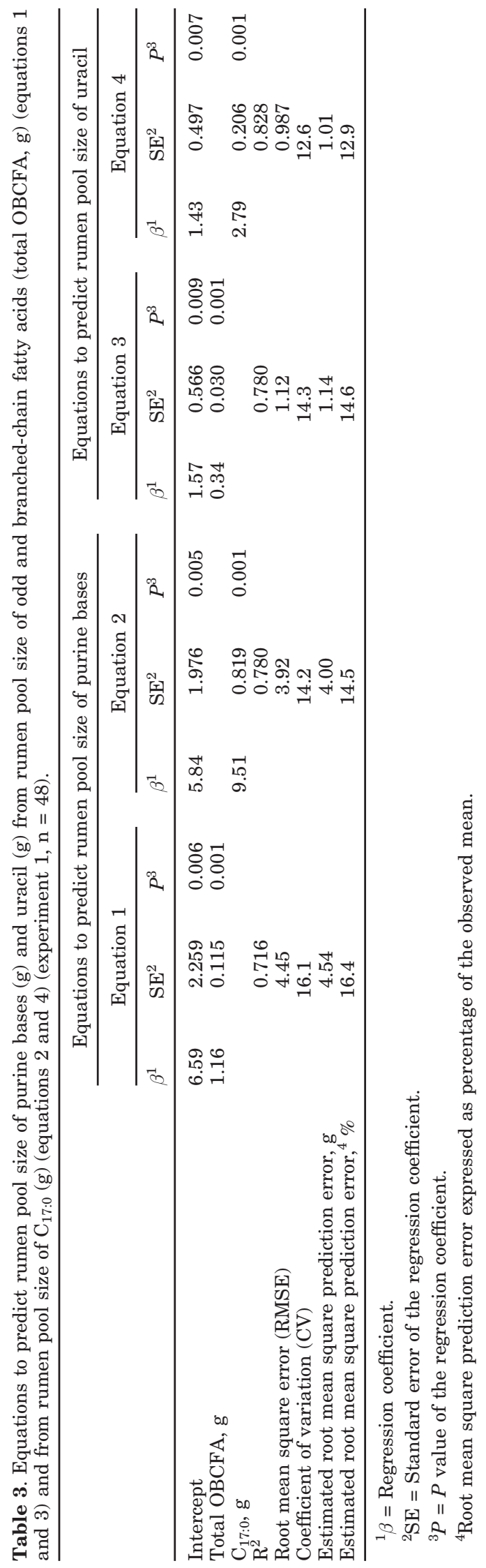



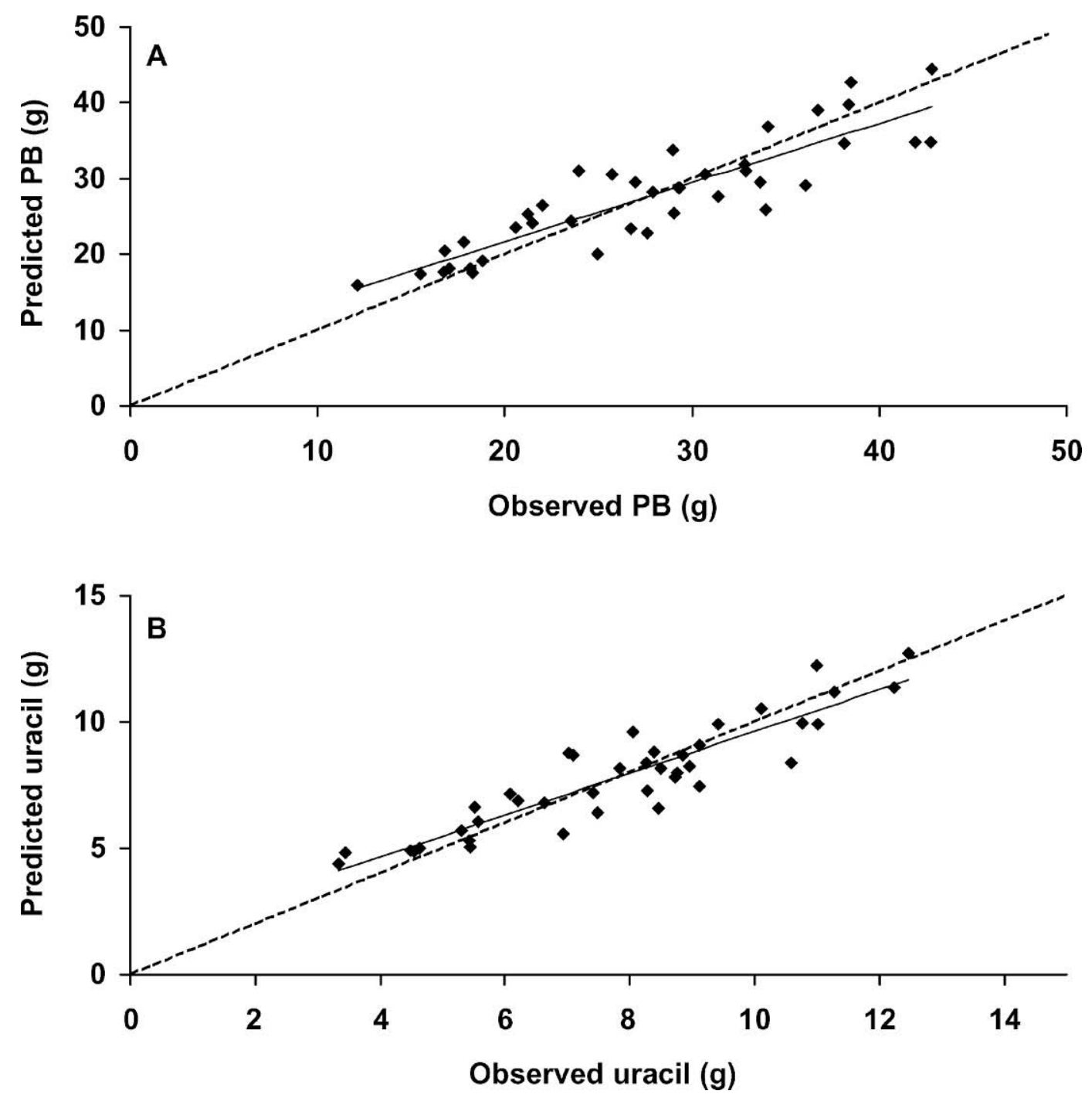

Figure 1. Plot of predicted vs. observed rumen pool size of A. purine bases (PB) and B. uracil. Regression equations are (A) predicted rumen pool size of $\mathrm{PB}=5.84+9.51 \times$ rumen pool size of $\mathrm{C}_{17: 0}$, and $(\mathrm{B})$ predicted rumen pool size of uracil $=1.43+2.79 \times$ rumen pool size of $\mathrm{C}_{17: 0}$.

respectively (equations 1 and 3 in Table 3 ). Because OBCFA and PB in rumen contents are the weighted sum of different microbial populations, it was anticipated that the ratio might be affected by variation in the composition of the rumen microbial population. Indeed, significant differences are reported in both OBCFA (Ifkovitz and Ragheb, 1968; Viviani, 1970), and uracil and PB contents (Arambel et al., 1982; Obispo and Dehority, 1999) between different strains of rumen bacteria. Particle-associated rumen bacteria contain generally more OBCFA (9.98 vs. $7.52 \mathrm{~g} / \mathrm{kg}$ of DM; Bauchart et al., 1990) compared with liquid-associated rumen bacteria. The opposite is true for $\mathrm{PB}$ and uracil [9.59 vs. $13.0 \mathrm{~g} / \mathrm{kg}$ of DM (Perez et al., 1997; Volden et al., 1999; Martin-Orue et al., 2000) and 2.57 vs. $2.68 \mathrm{~g} / \mathrm{kg}$ of DM (Volden et al., 1999) for PB and uracil, respectively]. Hence, variation in rumen proportions of particle- or fluid-associated bacteria clearly affects the ratios PB:OBCFA and uracil:OBCFA in mixed rumen bacteria. Although proportions of particle- and fluid-associated bacteria were not determined, the negative relation of time after feeding with the residuals from the equation relating OBCFA to $\mathrm{PB}$ $\left(\mathrm{r}_{\text {pearson }}=-0.542, P=0.001\right)$ or uracil $\left(\mathrm{r}_{\text {pearson }}=-0.528\right.$, $P=0.001)$ suggests that variation in the proportions of particle- and fluid-associated bacteria did occur in this experiment. The negative relation of the residuals with time after feeding indicates a relatively higher contribution to the rumen bacterial pool of fluid-associated bacteria $4 \mathrm{~h}$ after feeding compared with 12 
Table 4. Duodenal flow of purine bases, diaminopimelic acid (DAPA), and milk secretion of odd and branchedchain fatty acids (OBCFA), $\mathrm{C}_{17: 0}$, and $\mathrm{C}_{17: 1}$ from dairy cows fed diets containing concentrates with starches of different origins (experiment 2).

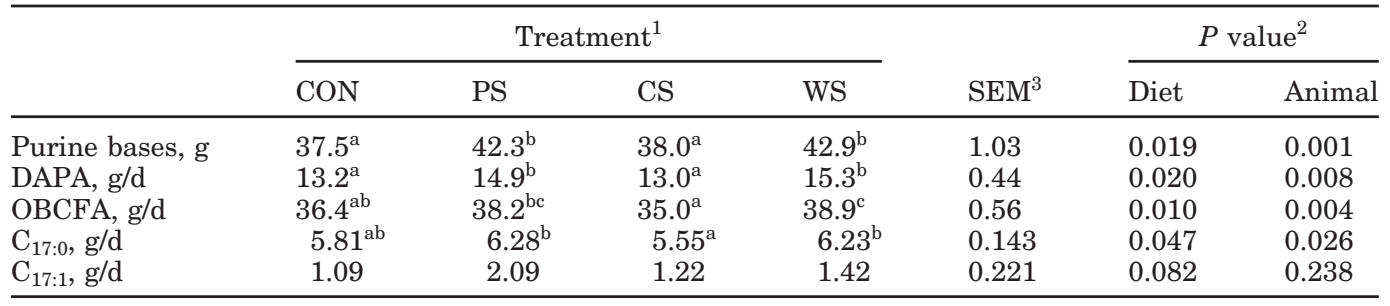

a,b,c Means within a row lacking a common superscript differ $(P<0.05)$.

${ }^{1}$ Treatments included a diet containing grass silage, sugar beet pulp, and a standard concentrate with dried beet pulp starch (CON), or a concentrate with potato starch (PS), corn meal (CS), or wheat meal (WS).

${ }^{2}$ Effect of dietary treatment and animal.

${ }^{3} \mathrm{SEM}=$ Standard error of the mean $(\mathrm{n}=4)$.

and $17 \mathrm{~h}$ after feeding. This finding is not surprising because fiber degradation and the contribution of particle-associated bacteria is expected to change with time after feeding.

Relation of rumen pool size of $C_{17: 0}$ with $P B$ and uracil. Although a strong relationship was observed between rumen pool size of OBCFA and microbial matter, it was affected by variation in the composition of the microbial population in the rumen. Little information is available on the ratio of individual OBCFA to $\mathrm{PB}$ and uracil in rumen bacteria, although data from Hussein et al. (1995) suggest relatively low variation in the ratio of $\mathrm{C}_{17: 0}$ to $\mathrm{PB}$ in mixed rumen bacteria. Because rumen OBCFA, PB, and uracil are of microbial origin, the ratios OBCFA:PB and OBCFA:uracil in whole rumen contents reflect the ratio in mixed rumen bacteria. In the current experiment, the ratio of $\mathrm{C}_{17: 0}$ to $\mathrm{PB}$ and of $\mathrm{C}_{17: 0}$ to uracil in rumen content was the least variable (data not shown). Hence, rumen pool size of $\mathrm{C}_{17: 0}$ (Table 2), instead of total OBCFA, was used to estimate rumen pool sizes of $\mathrm{PB}$ and uracil (equations 2 and 4 in Table 2; Figure 1).

\section{Relationship of Duodenal Flow of DAPA and PB with Milk Secretion of OBCFA (Experiment 2)}

The results of experiment 1 suggested that OBCFA in rumen contents are strongly related to microbial matter. However, for practical reasons, predictions of rumen microbial protein yield based on milk OBCFA would be of most value. Indeed, milk can be collected noninvasively and contains considerable amounts of microbially derived OBCFA (Fievez et al., 2003).

Duodenal flow of PB and DAPA. Dietary treatment influenced duodenal flow of microbial matter (Table 4). Flow of microbial matter to the duodenum was greater for the potato starch and wheat starch diet, probably due to differences between diets in true ruminally degraded $\mathrm{OM}$ and/or microbial growth efficiency (Oba and Allen, 2003). Duodenal flow of DAPA and $\mathrm{PB}$ were closely related $\left[\mathrm{PB}(\mathrm{g} / \mathrm{d})=2.87_{(\mathrm{SE}=0.043)}\right.$ $\times$ DAPA $\left.; \mathrm{n}=16 ; \mathrm{r}^{2}=0.997 ; \mathrm{RMSE}=2.38 \mathrm{~g} / \mathrm{d}\right]$.

Relation of milk secretion of $\mathrm{OBCFA}$ or $C_{17: 0}$ and $C_{17: 1}$ with duodenal flow of $P B$ and DAPA. Daily milk secretion of OBCFA was closely related to duodenal flow of DAPA and PB (equations 5 and 7 in Table 5). The prediction equations showed promising low CV of 10.6 and $10.1 \%$ for duodenal flow of PB and DAPA, respectively (equations 5 and 7 in Table 5). Indeed, the CV values obtained in the current experiment were in line with or considerably lower than CV values reported by others who developed equations to predict duodenal flow of microbial matter based on DMI and dietary characteristics (e.g., $\mathrm{CV}=8.2$ to $14.2 \%$, Oldick et al., 1999; CV $=29$ to $30 \%$, Gosselink et al., 2003). Nevertheless, direct comparison of CV values should be interpreted with caution, as residual variation in the predictive equations of Oldick et al. (1999) and Gosselink et al. (2003) might be partly due to the inherent variation in flow measurements and microbial markers used in the series of experiments of their databases. Obviously, this might not have been the origin of the residual variation of our predictive equations, as they were based on data of one experiment only. Despite the promising low CV, prediction equations based on milk secretion of OBCFA were biased, as indicated by the linear pattern in the residuals (data not shown).

As discussed before, this might be due to a varying ratio $\mathrm{OBCFA}$ to $\mathrm{PB}$, which is related to variation in mixed rumen bacteria. Hence, in accordance with relations in rumen contents, duodenal flow of microbial matter was related to milk secretion of straight-chain $\mathrm{C}_{17}$ fatty acids (i.e., $\mathrm{C}_{17: 0}$ and $\mathrm{C}_{17: 1}$ ). In contrast with relations in rumen content, $\mathrm{C}_{17: 1}$ was included in the prediction equation as this fatty acid is suggested to 
be mainly produced endogenously from $\mathrm{C}_{17: 0}$ in the mammary gland (Fievez et al., 2003). Prediction equations are presented in Table 5 (equations 6 and 8). These prediction equations were no longer biased (data not shown). However, we did not observe the expected decrease in the $\mathrm{CV}$ value when predictions were based on $\mathrm{C}_{17}$ fatty acids compared with predictions based on total OBCFA (Table 5).

Because earlier investigations of the predictive value of milk allantoin were partially discounted because of a mutual correlation with milk yield, it is worth noting that there was only a weak relationship between daily milk production and duodenal flow of microbial matter $\left(\mathrm{r}_{\text {pearson }}=0.160\right.$ and 0.361 for DAPA and PB flow, respectively, $P>0.10$ ) in the present study. In addition, milk production explained only $17.8 \%$ of the variation in milk secretion of OBCFA ( $P$ $>0.10$ ).

Evaluation of the prediction accuracy of equations based on milk OBCFA with independent data set. Although the relatively low estimated root MSPE, reasonably close to RMSE (Table 5), supports the validity of the fitted regression model (Neter et al., 1996), comparison of MSPE values obtained with an independent data set is the best way to evaluate the accuracy of different equations. The results of the present validation using an independent data set (Cabrita et al., 2003a,b) is presented in Figure 2. Predictions based on milk secretion of $\mathrm{C}_{17}$ fatty acids (equation 6) were more accurate compared with predictions based on milk secretion of OBCFA (equation 5), resulting in a root MSPE of 20.0 and $13.5 \%$ of the observed mean for equations 5 and 6 , respectively. Predictions based on milk secretion of OBCFA were less concordant compared with predictions based on $\mathrm{C}_{17}$ fatty acids (Figure 2). The lower CCC was mainly due to a lower accuracy $(0.633$ and 0.957 for equations 5 and 6 , respectively), whereas precision was higher for predictions based on milk secretion of OBCFA (0.851 and 0.753 for equations 5 and 6 , respectively). The lower accuracy for predictions based on milk secretion of OBCFA was attributed to a higher mean bias as illustrated by the higher location shift (1.06 and -0.090 for equations 5 and 6 , respectively) and the significant difference of the intercept from 0 when regressing predicted values on observed values (Figure 2). As depicted in Figure 2, the intercept and the slope of the regression of the predicted values on the observed values were not different from 0 and 1 , respectively, when regression was based on milk secretion of $\mathrm{C}_{17}$ fatty acids $(P<0.05)$.

In conclusion, prediction of duodenal flow of microbial matter seems relatively accurate when predic- 

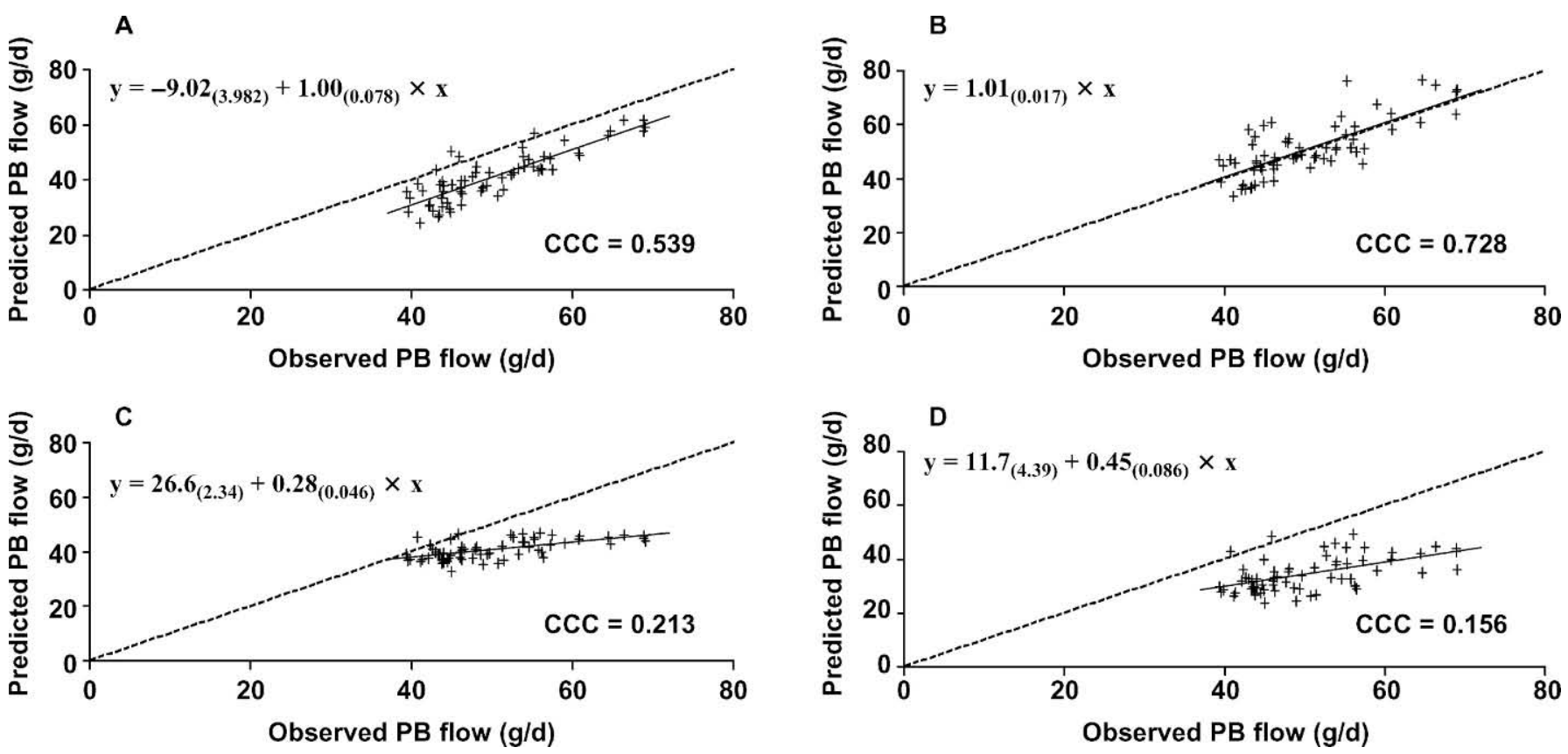

Figure 2. Plot of predicted vs. observed duodenal flow of purine bases (PB) with the concordance correlation coefficient (CCC) using milk secretion of odd and branched-chain fatty acids (A), milk secretion of straight-chain $\mathrm{C}_{17}$ fatty acids (B), and DMI and dietary characteristics (C, D). Regression equations used to predict duodenal flow of PB were (A) predicted duodenal flow of $\mathrm{PB}=1.10 \times$ milk secretion of odd and branched-chain fatty acids (equation 5), (B) predicted duodenal flow of $\mathrm{PB}=5.43 \times$ milk secretion of straight-chain $\mathrm{C}_{17}$-fatty acids (equation 6), (C) microbial N $(\mathrm{g} / \mathrm{d})=16.1+22.9 \times \mathrm{DMI}(\mathrm{kg} / \mathrm{d})-0.365 \times \mathrm{DMI}(\mathrm{kg} / \mathrm{d}) \times \mathrm{DMI}(\mathrm{kg} / \mathrm{d})-0.174 \times \mathrm{NDF}(\mathrm{g} / \mathrm{kg}$ of DM) [equation 10 in Oldick et al. (1999)], and (D) microbial N $(\mathrm{g} / \mathrm{d})=(7.80+0.000119 \times$ crude protein $(\mathrm{g} / \mathrm{kg}$ of DM) $) \times \mathrm{DMI}(\mathrm{kg} / \mathrm{d})$ [equation 3 in Gosselink et al. $(2003)]$.

tions are based on milk secretion of OBCFA, in particular $\mathrm{C}_{17}$ fatty acids.

Comparison of the prediction equations based on milk OBCFA with published prediction equations based on DMI and dietary characteristics. The root MSPE values of the equation reported by Oldick et al. (1999) (22.6\%) and the equation based on the secretion of OBCFA (equation 5) were similar. The equation of Gosselink et al. (2003) was the least accurate, with a root MSPE of the observed mean of $34.5 \%$. Both equations based on DMI and dietary characteristics (Oldick et al., 1999, Gosselink et al., 2003) showed low CCC values, which was mainly due to a relatively low accuracy ( 0.347 and 0.283 for equations of Oldick et al., 1999 and Gosselink et al., 2003, respectively). Indeed, predictions based on DMI and dietary characteristics (Oldick et al., 1999, Gosselink et al., 2003) were not able to accurately reflect changes in microbial flow to the duodenum, as additionally indicated by the low standard deviation of the predicted values (Figure 2). It should be noted that the original data sets used by Oldick et al. (1999) and Gosselink et al. (2003) for estimation of the regression equations were treatment means, resulting in predictions of duodenal flow of microbial matter for an "average cow." In contrast, regression equations developed in this study were based on individual cow observations as animals notoriously vary in duodenal flow of microbial matter on the same diet. These differences are accounted for when using milk OBCFA, but are largely neglected in equations based on dietary characteristics only.

In general, prediction of duodenal flow of microbial matter seems most accurate when based on milk secretion of OBCFA, and in particular, $\mathrm{C}_{17}$ fatty acids. Nevertheless, as more data become available, more trials will be included in this kind of evaluation to ensure the evaluation is not biased by trial effects.

This first evaluation suggests that milk OBCFA could be used as a marker for microbial material, particularly when accurate measurements of DMI are lacking. Moreover, predictive equations in this first evaluation were developed using a relatively small data set with limited variation in dietary treatments. Hence, it is suspected that enlarging the data set will result in more accurate prediction equations. Enlarging the data set with additional experiments is currently in progress. Additionally, the effect of dietary fat levels on this relationship should be elucidated, as dairy cows were not fed supplemental fat in the current experiments. Indeed, increased dietary fat supply (mainly 18-carbon fatty acids and $\mathrm{C}_{16: 0}$ ) reduces the proportion of OBCFA in duodenal contents and milk 
(Fievez et al., 2003). This decrease in OBCFA with higher dietary fat levels may be due to (partial) inhibition of de novo synthesis of OBCFA by rumen bacteria at higher dietary fat levels (Demeyer et al., 1978) or dilution with greater concentrations of even-chain fatty acids in milk. Furthermore, additional studies are needed to identify the effects of other factors, such as lactation stage and contribution of OBCFA from body fat to milk OBCFA, particularly during periods of negative energy balance and parity.

\section{CONCLUSIONS}

Rumen OBCFA showed strong relationships with microbial matter in the rumen and milk secretion of OBCFA, in particular $\mathrm{C}_{17}$ fatty acids, showed potential to predict duodenal flow of microbial biomass. Moreover, the latter regression equation was more accurate compared with previously published prediction equations based on DMI and dietary characteristics (Oldick et al., 1999; Gosselink et al., 2003). Hence, measurement of milk OBCFA could give insight in the microbial flow to the duodenum in nonfistulated dairy cows. This noninvasive method would be highly advantageous both in practical dairy cattle feeding as well as for research purposes. However, to fully exploit the potential of these milk parameters, more experiments are needed to substantiate the current findings.

\section{ACKNOWLEDGMENTS}

The Ph.D. research of Bruno Vlaeminck is supported by the Institute for the Promotion of Innovation through Science and Technology in Flanders.

\section{REFERENCES}

Arambel, M. K., E. E. Bartley, G. S. Dufva, T. G. Nagaraja, and A. D. Dayton. 1982. Effect of diet on amino and nucleic acids of rumen bacteria and protozoa. J. Dairy Sci. 65:2095-2101.

Bas, P., H. Archimede, A. Rozeau, and D. Sauvant. 2003. Fatty acid composition of mixed-rumen bacteria: effect of concentration and type of forage. J. Dairy Sci. 86:2940-2948.

Bauchart, D., F. Legay-Carmier, M. Doreau, and B. Gaillard. 1990. Lipid metabolism of liquid-associated and solid-adherent bacteria in rumen contents of dairy cows offered lipid-supplemented diets. Br. J. Nutr. 63:563-578.

Bibby, J., and H. Toutenberg. 1977. Prediction and improvement estimation in linear models. John Wiley \& Sons, London, UK.

Bruinenberg, M. H., H. Valk, P. C. Struik, and A. M. van Vuuren. 2004. Fermentation and degradation in the rumen of dairy cows fed on diets consisting of silage from an intensively managed sward and silages from semi-natural grasslands. J. Agric. Sci. 142:79-88

Cabrita, A. R. J., A. J. M. Fonseca, R. J. Dewhurst, C. V. P. Sampaio, M. F. S. Miranda, G. N. S. Sousa, I. M. F. Miranda, and E. Gomes. 2003a. Nitrogen Supplementation of Corn Silages. 1. Effects on feed intake and milk production of dairy cows. J. Dairy Sci. 86:4008-4019.

Cabrita, A. R. J., A. J. M. Fonseca, R. J. Dewhurst, and E. Gomes. 2003b. Nitrogen supplementation of corn silages. 2. Assessing rumen function using fatty acid profiles of bovine milk. J. Dairy Sci. 86:4020-4032.

Chen, X. B., and M. J. Gomes. 1995. Estimation of microbial protein supply to sheep and cattle based on urinary excretion of purine derivatives-an overview of the technical details. Occasional publication 1992, International Feed Resources Unit, Rowett Research Institute, Aberdeen. Online. Available http:// www.mluri.sari.ac.uk/IFRU/chema.pdf. Accessed Jan. 29, 2004.

Clark, J. H., T. H. Klusmeyer, and M. R. Cameron. 1992. Microbial protein synthesis and flows of nitrogen fractions to the duodenum of dairy cows. J. Dairy Sci. 75:2304-2323.

Croom, W. J., D. E. Bauman, and C. L. Davis. 1981. Methylmalonic acid in low-fat milk syndrome. J. Dairy Sci. 64:649-654.

Demeyer, D. I., C. Henderson, and R. A. Prins. 1978. Relative significance of exogenous and de novo synthesized fatty acids in formation of rumen microbial lipids in vitro. Appl. Environ. Microbiol. 35:24-31.

Dewhurst, R. J., D. R. Davies, and R. J. Merry. 2000. Microbial protein supply from the rumen. Anim. Feed Sci. Technol. 85:1-21.

Draper, N. R., and H. Smith. 1981. Applied Regression Analysis. 2nd ed. John Wiley \& Sons, New York, NY.

Faichney, G. J. 1992. Effect of non-uniform distribution of particleassociated markers on the measurement of duodenal digesta flow by the double-marker technique. J. Agric. Sci. 118:119-120.

Fievez, V., B. Vlaeminck, M. S. Dhanoa, and R. J. Dewhurst. 2003. Use of principal component analysis to investigate the origin of heptadecenoic and conjugated linoleic acids in milk. J. Dairy Sci. 86:4047-4053.

Folch, J., M. Lees, and G. H. Sloane-Stanley. 1957. A simple method for isolation and purification of total lipids from animal tissues. J. Biol. Chem. 226:497-509.

Gonzalez-Ronquillo, M., J. Balcells, J. A. Guada, and F. Vicente. 2003. Purine derivative excretion in dairy cows: Endogenous excretion and the effect of exogenous nucleic acid supply. J. Dairy Sci. 86:1282-1291.

Gosselink, J. M. J., C. Poncet, J.-P. Dulphy, and J. W. Cone. 2003. Estimation of the duodenal flow of microbial nitrogen in ruminants based on the chemical composition of forages: A literature review. Anim. Res. 52:229-243.

Hindle, V. A., A. M. van Vuuren, A. Klop, A. A. Mathijssen-Kamman, A. H. van Gelder, and J. W. Cone. Site and extent of starch degradation in the dairy cow. A comparison between in vivo, in situ, and in vitro measurements. J. Anim. Physiol. Anim. Nutr. (accepted)

Hussein, H. S., N. R. Merchen, and G. C. Fahey. 1995. Composition of ruminal bacteria harvested from steers as influenced by dietary forage level and fat supplementation. J. Anim. Sci. 73:24692473.

Ifkovitz, R. W., and H. S. Ragheb. 1968. Cellular fatty acid composition and identification of rumen bacteria. Appl. Microbiol. 16:1406-1413.

Kaneda, T. 1991. Iso- and anteiso-fatty acids in bacteria: Biosynthesis, function, and taxonomic significance. Microbiol. Rev. 55:288-302.

Keeney, M., I. Katz, and M. J. Allison. 1962. On the probable origin of some milk fat acids in rumen microbial lipids. J. Am. Oil Chem. Soc. 39:198-201.

Lin, L. I. 1989. A concordance correlation-coefficient to evaluate reproducibility. Biometrics 45:255-268.

MacRae, J. C., and S. Wilson. 1977. The effects of various forms of gastrointestinal cannulation on digestive measurements in sheep. Br. J. Nutr. 38:65-71.

Makkar, H. P. S., and K. Becker. 1999. Purine quantification in digests from ruminants by spectrophotometric and HPLC methods. Br. J. Nutr. 81:107-112.

Martin-Orue, S. M., J. Balcells, J. A. Guada, and M. Fondevila. 2000. Microbial nitrogen production in growing heifers: direct measurement of duodenal flow of purine bases versus urinary excretion of purine derivatives as estimation procedures. Anim. Feed Sci. Technol. 88:171-188. 
Massart-Leën, A. M., E. Roets, G. Peeters, and R. Verbeke. 1983. Propionate for fatty acid synthesis by the mammary gland of the lactating goat. J. Dairy Sci. 66:1445-1454.

McAllan, A. B. 1982. The fate of nucleic acids in ruminants. Proc. Nutr. Soc. 41:309-317.

Moore, S., D. H. Spackman, and W. H. Stein. 1985. Chromatography of amino acids on sulfonated polystyrene resins. Anal. Chem. 30:1185-1190.

Neter, J., M. H. Kutner, W. Wasserman, and C. J. Nachtsheim. 1996. Applied Linear Statistical Models. 4th ed. McGraw-Hill/ Irwin, Burr Ridge, IL.

Oba, M., and M. S. Allen. 2003. Effects of diet fermentability on efficiency of microbial nitrogen production in lactating dairy cows. J. Dairy Sci. 86:195-207.

Obispo, N. E., and B. A. Dehority. 1999. Feasibility of using total purines as a marker for ruminal bacteria. J. Anim. Sci. 77:3084-3095.

Oldick, B. S., J. L. Firkins, and N. R. St-Pierre. 1999. Estimation of microbial nitrogen flow to the duodenum of cattle based on dry matter intake and diet composition. J. Dairy Sci. 82:1497-1511.

Perez, J. F., J. Balcells, J. A. Guada, and C. Castrillo. 1997. Rumen microbial production estimated either from urinary purine derivative excretion or from direct measurements of $\mathrm{N}-15$ and purine bases as microbial markers: Effect of protein source and rumen bacteria isolates. Anim. Sci. 65:225-236.
Raes, K., S. De Smet, and D. Demeyer. 2001. Effect of doublemuscling in Belgian Blue young bulls on the intra muscular fatty acid composition with emphasis on conjugated linoleic acid and poly-unsaturated fatty acids. Anim. Sci. 73:253-260.

Rawlings, J. O. 1988. Applied Regression Analysis. A Research Tool. 1st ed. Wadsworth, Inc., Belmont, CA.

St-Pierre, N. R. 2003. A concordance coefficient to compare model predictions to observed data. J. Dairy Sci. 86(Suppl. 1):172. (Abstr.)

van Vuuren, A. M., V. A. Hindle, and J. W. Cone. 2004. Effect of starch source on supply of glycogenic nutrients in dairy cows. J. Dairy Sci. 83(Suppl. 1):463. (Abstr.)

Viviani, R. 1970. Metabolism of long-chain fatty acids in the rumen. Adv. Lipid Res. 8:267-346.

Viviani, R., A. R. Boragtti, and G. Gentile. 1967. Effect of antibiotics on long chain fatty acids and DNA in cattle rumen fluid. Zbl. Vet. Med. A 14:189-197.

Vlaeminck, B., V. Fievez, M. S. Dhanoa, A. van Vuuren, and R. Dewhurst. 2003. Prediction of rumen volatile fatty acids based on milk fatty acid profiles. Pages 569-572 in EAAP Publication No. 109. W. B. Souffrant, and C. C. Metges, ed. Wageningen Academic Publishers, Wageningen, The Netherlands.

Volden, H., L. T. Mydland, and O. M. Harstad. 1999. Chemical composition of protozoal and bacterial fractions isolated from ruminal contents of dairy cows fed diets differing in nitrogen supplementation. Acta Agric. Scand. A 49:235-244. 